\title{
Diabetes NetPLAY: A physical activity website and linked email counselling randomized intervention for individuals with type 2 diabetes
}

\author{
Tanis Liebreich ${ }^{1}$, Ronald C Plotnikoff*2, Kerry S Courneya ${ }^{3}$ and \\ Normand Boulé 3
}

\begin{abstract}
Address: ${ }^{1}$ Centre for Health Promotion Studies, School of Public Health, 5-10 University Terrace, 8303 - 112 Street, University of Alberta, Edmonton, Alberta, T6G 2T4, Canada, ${ }^{2}$ Centre for Health Promotion Studies, School of Public Health, and Faculty of Physical Education and Recreation, 5-10 University Terrace, 8303 - 112 Street, University of Alberta, Edmonton, Alberta, T6G 2T4, Canada and ${ }^{3}$ Faculty of Physical Education and Recreation, E-488 Van Vliet Centre, University of Alberta, Edmonton, Alberta, T6G 2H9, Canada
\end{abstract}

Email: Tanis Liebreich - tanis_liebreich@phac-aspc.gc.ca; Ronald C Plotnikoff* - ron.plotnikoff@ualberta.ca; Kerry S Courneya - kerry.courneya@ualberta.ca; Normand Boulé - nboule@ualberta.ca

* Corresponding author

Published: 27 March 2009

International Journal of Behavioral Nutrition and Physical Activity 2009, 6:18 doi:10.1186/1479-5868-6-18

This article is available from: http://www.ijbnpa.org/content/6/1/18

(c) 2009 Liebreich et al; licensee BioMed Central Ltd.

This is an Open Access article distributed under the terms of the Creative Commons Attribution License (http://creativecommons.org/licenses/by/2.0), which permits unrestricted use, distribution, and reproduction in any medium, provided the original work is properly cited.
Received: 28 November 2008

Accepted: 27 March 2009

\begin{abstract}
Background -: This pilot study evaluated the feasibility (recruitment, retention, adherence and satisfaction) and preliminary efficacy of a I2-week website and email-linked counselling intervention on physical activity behaviour change in individuals with type 2 diabetes.

Methods -: A total of 49 individuals with type 2 diabetes (59\% female, average age 54 . I years) were randomized to the Diabetes NetPLAY intervention or control condition. The intervention condition received information grounded in the Social Cognitive Theory (SCT), personalized weekly emails, an on-line logbook and message board. Key outcomes included physical activity behaviour and related cognition changes. The control condition was provided links to the Canadian Diabetes Association's Clinical Practice Guidelines for Physical Activity and Canada's Guide to Physical Activity.

Results -: Intervention participants indicated high levels of satisfaction for this mode of delivery and study results demonstrated the feasibility of web-based mediums for the delivery of physical activity information in this population. The intervention group demonstrated a significant improvement in total vigorous and moderate minutes of physical activity $(p=0.05)$ compared to the control group over the 12-week study. Among the SCT variables, behavioural capacity, showed a significant increase $(\mathrm{P}<0.00 \mathrm{I})$ among intervention participants.
\end{abstract}

Conclusion -: Web-based interventions for individuals with type 2 diabetes are feasible and show promise for improving positive physical activity outcomes.

\section{Background}

Physical activity has long been recognized as one of the cornerstones of diabetes management [1]. Physical activity, including aerobic and resistance training, can assist individuals with type 2 diabetes in achieving a variety of goals including improved glycemic control, increased cardiorespiratory fitness, decreased insulin resistance, improved lipid profile and weight management [2]. 
Moderate to high levels of cardiorespiratory fitness in those with type 2 diabetes has been associated with a 45$70 \%$ reduction in both cardiovascular and overall mortality [3].

The Canadian Diabetes Association's Clinical Practice Guidelines recommend those with type 2 diabetes accumulate at least 150 minutes of moderate intensity aerobic activity per week spread over at least three non-consecutive days [4]. However, individuals with diabetes report high inactivity rates, with more than $60 \%$ of adults not meeting recommended physical activity guidelines $[5,6]$.

The internet offers a unique opportunity for delivering innovative, large scale behavioural change interventions, including physical activity [7-10]. Several advantages exist for internet health technology. Information is available to users 24 hours a day allowing for information to be viewed at their convenience. It also houses components such as chat rooms and web conferencing which can facilitate social support and communication from other users and health care providers [11]. However, the internet can pose obstacles for individuals as well. Low-income households report reduced rates of computer and internet usage [12]. Access to internet technology in rural areas can be limited or only available via dial-up technology. Literacy levels and computer skills are also potential barriers that individuals may face when using this type of technology to access health information.

According to Statistics Canada [12], 64\% of Canadian households had at least one member who accessed the Internet regularly either from home, work, school, public library or another location. Of internet users, $84 \%$ report having access to email with 39\% using it everyday to communicate and $25 \%$ making use of email at least once a week. Additionally, more people are using the internet to find health information, making it the third most searched topic behind email and general browsing. For these reasons the internet, and specifically email, can be considered as a potential channel for the administration and delivery of physical activity interventions [13].

The use of interactive technology to change behaviour is expanding the scope and flexibility of intervention and teaching options [14]. The use of internet technology and e-counselling techniques has shown promising results in the weight loss $[15,16]$, nutrition $[17,18]$, and physical activity domains [13,19-23].

In the physical activity domain, Plotnikoff and colleagues [19] assessed the efficacy of a 12-week email physical activity and nutrition intervention on knowledge, attitude and behaviour change in a large workplace sample. At the conclusion of the study, the intervention group had significantly increased their total activity levels and reported higher confidence and intention levels related to physical activity participation compared to the control group.

Napolitano et al. [13] tested the efficacy of a theoreticallybased physical activity website plus 12 weekly email tip sheets on a sample of sedentary employees of several large hospitals. At 1-month follow-up, participants in the intervention group demonstrated significantly more minutes of moderate physical activity and walking minutes per week. Additionally, a greater proportion of those in the intervention group progressed in stage of motivational readiness than those in the control. At 3-months followup, those individuals in the intervention group were more likely to progress in stage of motivational readiness than individuals in the control.

There is a growing number of websites targeting diabetes education and support; however, the use of interactive computer technology to increase physical activity behaviour in individuals with type 2 diabetes is in its infancy. In light of this new technology base there is little empirical evidence that such interventions improve the outcomes and quality of life of those who participate in them $[8,24]$.

In one of the first studies in this domain, McKay and colleagues [11] conducted an 8-week pilot study to evaluate the feasibility and impact of the Internet-based Diabetes Network (D-Net) Active Lives Physical Activity Intervention. A total of 78 individuals with type 2 diabetes were randomized to the D-Net intervention site or to an internet-information only condition. At the 8-week follow-up, results indicated an overall moderate improvement in physical activity levels within both groups, with no significant improvement in regard to condition effects. Among participants in the intervention group, those who utilized the site more regularly obtained significantly greater benefits compared to the control group who demonstrated only modest improvements with increased program use.

Theoretical approaches have been used not only to understand physical activity as a behaviour but also to provide the conceptual and empirical knowledge base for the design of activity promoting programs. To provide guidance for the design of effective programs, such as webbased strategies, interventions must be grounded in behaviour change theory [25].

One of the major behaviour change theories is the Social Cognitive Theory (SCT) as presented by Bandura [26], which postulates that personal, behavioural, and environmental factors operate as reciprocal interacting determinants of human functioning. Furthermore, the notion of reciprocal determinism suggests that individuals are both agents and recipients of their behaviours. According to Bandura $[27,28]$ a number of crucial factors influence behaviour. These core determinants include knowledge of 
health risks and benefits of different health practices, perceived self-efficacy that one can exercise control over their individual health habits, the health-related goals they set for themselves and the specific plans and strategies for realizing them, as well as the perceived facilitators and impediments to the changes they strive for. Other critical factors included in the SCT are the individuals' capabilities to symbolize behaviour, to learn by observing others, to have confidence in performing a behaviour, to self-regulate or self-determine behaviour and to reflect on and analyze experience [27]. Baranowski, Perry \& Parcel [29] present the social cognitive theory as ten specific constructs: self-efficacy, self-regulation, outcome expectations, outcome expectancies, behavioural capacity, observational learning, reinforcement, emotional coping response, perceived environment and situation.

SCT has been acknowledged as one of the leading health behaviour change theories used to explain and predict physical activity $[30,31]$ in the general population and in those with type 2 diabetes [32]. SCT has been applied to several diabetes management studies aimed at increasing physical activity in this population [33,34]. The First Step Pedometer Program developed by Tudor-Locke and colleagues [33] operationalized self-efficacy and outcome expectations from SCT with the short-term goal of increasing physical activity (walking) in overweight/obese individuals with diabetes. At the conclusion of the 24-week follow-up, the intervention group had increased their physical activity by 3000 steps/day or approximately 30 minutes/day $(\mathrm{p}<0.001)$ compared with that of the control group.

Di Loreto and colleagues [34] developed a counselling strategy, based on self-efficacy and outcome expectations constructs from SCT, to increase physical activity behaviour in individuals with type 2 diabetes. In this study, 342 individuals were randomized to either an intervention or control group. At the two-year follow-up, results indicated the intervention group, compared to the control group, significantly increased energy expenditure seven-fold ( $\mathrm{p}<$ 0.001 ) with significant improvements also reported in HbA1c and BMI.

In summary, the use of web-based technology to deliver physical activity information relevant to those living with type 2 diabetes is expanding. However, further research on designing and testing theoretically grounded web-based interventions is needed for changing health behaviour in this population.

The purpose of this study is to explore the feasibility and preliminary efficacy of a website and email-linked counselling intervention on physical activity behaviour change in individuals with type 2 diabetes. We examine the feasibility (recruitment, retention, adherence and satisfaction) of the internet as a mode of delivery for diabetes related physical activity information for individuals with type 2 diabetes. In addition, the preliminary efficacy of the internet as a mode of delivery for eliciting recommended changes in physical activity related cognitions and behaviours for individuals with type 2 diabetes is also examined. We hypothesize that physical activity-related cognitions and behaviours will increase in the intervention group when compared to the control group after 12 weeks.

\section{Methods \\ Design}

The study was a prospective, two-armed, randomized controlled trial. Participants were randomly assigned to either the intervention or control condition.

\section{Recruitment}

A sample of men and women with type 2 diabetes were recruited through diabetes education classes, newspaper advertisements, recruitment posters, health care professionals and previous research involvement. Interested respondents were screened via telephone/in person for participation criteria and, if eligible, informed consent was obtained. Inclusion criteria included a diagnosis of type 2 diabetes, being over the age of 18 and having access to the internet and email. Contraindications for physical activity were accessed by the Physical Activity Readiness Questionnaire (PAR-Q) [35]. Participants who indicated a contraindication to physical activity based on the PAR-Q were required to provide written consent from a primary care physician.

A total of 235 study information packages were distributed over the 3 month recruitment period. Seventy-eight individuals responded to the information packages, with 50 providing consent to participate. Of those individuals that did not give consent, 11 were not interested in the study, 8 indicated other commitments and another 9 failed to return the required consent forms. One individual failed to be reached after consent to participate in the study was given (see Figure 1: Study Flow Diagram). Ethical clearance for this study was obtained from a universitybased, ethics committee.

\section{Procedures}

Upon recruitment deadline, all eligible participants completed an on-line questionnaire assessing baseline measurements of physical activity behaviour, physical activityrelated cognitions and demographic characteristics. Upon completion, participant names were randomized with equal probability into one of two groups: intervention group or the control group. A total of 49 individuals with type 2 diabetes were randomly assigned into the control condition $(n=24)$ or Diabetes NetPLAY intervention group $(n=25)$. Participants were then informed via email 


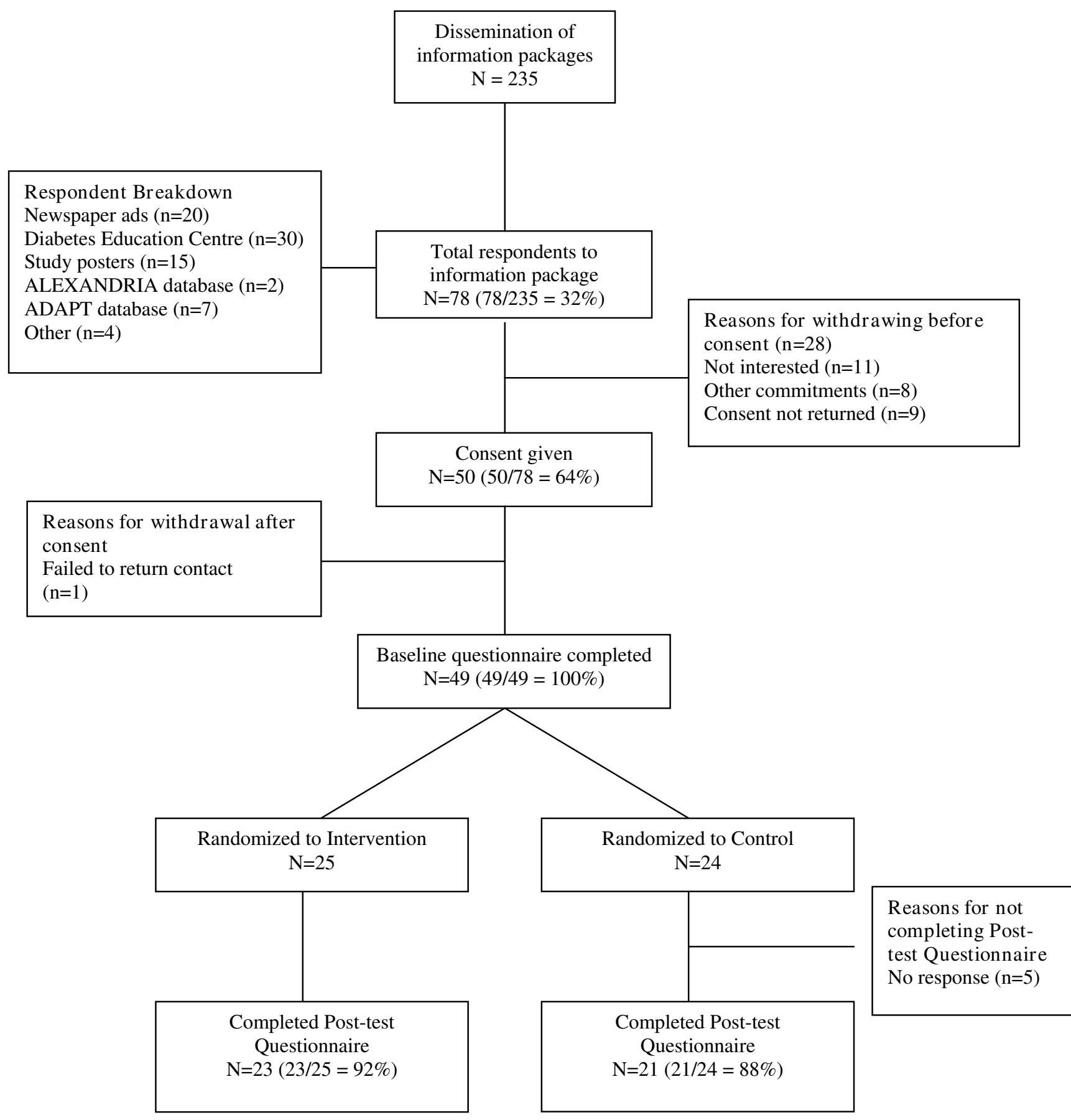

Figure I

Study Flow Diagram.

of their group assignment and were provided with confidential usernames and password to access the appropriate website.

\section{Diabetes NetPLAY intervention group}

The Diabetes NetPLAY program was designed based on Bandura's [27] Social Cognitive Theory (SCT) and aimed to provide participants with the education and skills important for long term behaviour change. The website was comprised of five main sections (weekly topic, education, research, fitness tips and physical activity myths) which were updated and archived on a weekly basis. The website also contained several interactive features to engage participants through the duration of the study. 
These features included a physical activity logbook, message board and weekly email counselling from the study coordinator. Participants in the intervention group also received links to the Canadian Diabetes Association's Clinical Practice Guidelines [4] for physical activity in addition to Health Canada's Physical Activity Guide http:/ /www.phac-aspc.gc.ca/pau-uap/fitness/downloads.html.

Each week featured a new theme based on a specific construct of SCT. This weekly topic aimed to operationalize the SCT construct in a way that would be meaningful to the participant. As a way of invoking thoughts and actions around the various constructs, participants were asked to complete an activity and email responses to the study coordinator. Goal setting and time management were some of the activities discussed.

\section{Physical activity logbook}

Participants in the intervention group were encouraged to log their physical activity minutes using the on-line logbook section of the website. The logbook allowed for participants to track the date, length, and type of physical activity they engaged in. This feature also allowed them to write comments beside their activity sessions and track their progress from day-to-day.

\section{Message board}

The message board feature was launched in the second week of the study. The study coordinator posted weekly topics based on the social cognitive construct featured that week. Participants could respond and view postings at their leisure. This allowed participants a forum in which to exchange ideas and receive support from other study participants.

\section{Email counselling}

The email counselling feature of the website allowed participants the opportunity to communicate with their counsellor (study coordinator) in a simple and efficient way. Beginning in the first week, participants were asked to email their counsellor with responses to the relevant topic discussed; however, participants could communicate with their counsellor via email at any time throughout the week on topics of importance to them. If participants failed to contact their counsellor on any given week, a brief email checking in on the participant was sent as a reminder.

Qualifications for the study counsellor included a Bachelors of Science in Physical Education and a Masters of Science in Health Promotion with a strong focus in behaviour change theory, diabetes and physical activity.

\section{Control ('Standard Care') condition}

The control group received static links to the Canadian Diabetes Association's Clinical Practice Guidelines [4] for physical activity and Health Canada's Physical Activity Guide http://www.phac-aspc.gc.ca/pau-uap/fitness/ downloads.html(as 'Standard Care' material) on the control website for the duration of the 12-week study. Control participants were not given any specific instruction/ indication on what their physical activity behaviour should entail for the proceeding 3 months (study commencement). Participants were contacted at the end of week 12 and provided a link to the post-test questionnaire. Upon completion of the post-test questionnaire, control group participants were given full access (minus email counselling feature) to the study website. As the website was no longer being maintained and updated, these participants were directed to the archived items to review each of the 12 weeks at their leisure. Incentives were offered to control participants upon completion of the post-test questionnaire. Incentives included full access to the study website and a choice of a pedometer and water bottle or a $\$ 25$ gift certificate to a national bookstore chain.

\section{Measures}

All measures were administered on-line at baseline and at the end of the 12-week study. Reminder emails were sent if participants failed to complete questionnaires within 10 days of initial administration.

Baseline demographic variables were included based on various socio-demographic measures from Statistics Canada [36]. Participants were asked age, gender, marital status, English as a first language, education, current employment status, and gross annual family income. A physical activity disability measure was assessed using previously published self-report measure [6]. Participants were also asked to report their height (in feet/inches or meters/centimetres) and weight (in pounds or kilograms), in order to calculate BMI $\left(\mathrm{kg} / \mathrm{m}^{2}\right)$. BMI categories were defined by Health Canada [37]. Finally, computer usage data were collected using items from Statistics Canada's Household Internet Use Survey [12].

\section{Physical Activity}

Leisure-time physical activity (LTPA) was assessed using a modified version [6] of the validated Godin Leisure-Time Exercise Questionnaire (GLTEQ) [38]. In this instance, LTPA was defined as a physical activity session longer than 10 minutes in duration and was not part of employment or household chores. Based on an average of the past month, participants were asked to report: (1) frequency (times per week), and, (2) duration (average time per session), of activity in each intensity category (strenuous, moderate or mild). The reliability of the GLTEQ has been independently evaluated and found to compare favourably to nine other measures of self-report exercise, objective monitors, and fitness indices [39]. Participation responses were then converted into: (1) MET minutes by 
multiplying weekly minutes of moderate activity by 4 METS and vigorous activity by 7.5 METS [40]; and, (2) unweighted minutes by summing weekly minutes of moderate and vigorous physical activity.

Mild activity levels were not included in either calculation for three reasons: (1) all psychosocial variables are based on a definition of physical activity of moderate or greater intensity; (2) population-based MET values have only been defined for moderate activity or greater [40]; and, (3) the Canadian Diabetes Association's Clinical Practice Guidelines [4] state that moderate to high levels of physical activity are associated with substantial decreases in mortality and morbidity in individuals with type 2 diabetes. Although not included in the outcome measure, mild intensity physical activity is still important to the overall health of those individuals with type 2 diabetes, especially for those who have been sedentary in the past.

A resistance training (RT) measure was also incorporated into the GLTEQ in which participants were asked to report on average in the past month, frequency (times per week), and duration (average times per session) they had engaged in resistance training activities. Participation responses were captured by multiplying frequency by duration to produce a final RT score.

\section{Social Cognitive Measures}

\section{Self-efficacy}

Self-efficacy was assessed using a validated 12-item scale [41]. Each item was measured on a five-point Likert-type scale ( 1 = strongly disagree; 5 = strongly agree) and asked individuals to rate their confidence over the next 3 months in performing regular physical activity in a variety of circumstances (e.g., when tired, when busy, during bad weather).

\section{Outcome expectations}

Outcome expectations was assessed using a five-point Likert-type scale with response options ranging from "strongly disagree" (1) to "strongly agree" (5), and had participants rate their agreement with 17 expectation items of engaging in regular physical activity. A sample item from this scale was "I will feel better physically if I get regular physical activity." The outcome expectations measure was adapted from two sources: (1) the decisional balance scale originally designed by Marcus, Rawkoski, \& Rossi [42], and adapted for a Canadian population by Plotnikoff et al. [43]; and (2) the physical activity expectations scale used in the PARR project [44]. Both sets if items were framed 'for the next 3 months.'

\section{Outcome expectancies}

The outcome expectancies scale had participants rate on a three-point Likert-type scale ( 1 = unimportant; 3 = very important) the perceived importance of the 17 previously stated expectation items. An example of an item from this scale was "How important is feeling better physically to you?" This scale was adapted from the PARR project [44], which had originally been created, tested and utilized with a low income population.

\section{Self-regulation}

The self-regulation measure was adapted from a subscale of the Behaviour Regulation in Exercise Questionnaire (BREQ-2) [45] identified for exercise regulation. The three-item scale had participants indicate how true a variety of reasons were (e.g., 'I value the benefits of exercise') for them participating in regular physical activity, with response items ranging from "not at all true" (1) to "very true" (5).

\section{Situation}

The situation construct was measured by having participants indicate how often in the past three months various situations prevented them from getting regular physical activity. Response options for this 17-item scale ranged from "never" (1) to "very often" (5) and were adapted from a previous physical activity scale used in a study of breast cancer survivors [46].

\section{Reinforcement}

Reinforcement was measured using a five-point Likerttype scale with responses ranging from "never" (1) to "always" (5). Participants were asked to specify how often in the last three months they had rewarded themselves and set realistic goals. A sample question from this four item scale developed by Marcus, Rossi, Shelby, Niaura and Abrams [47], is "I reward myself when I am physically active."

\section{Social Support}

The social support measure, previously used by Courneya, Plotnikoff, Hotz \& Birkett [48], consisted of two items measured on a 7-point Likert-type scale with options ranging from "strongly disagree" (1) to "strongly agree" (7). A sample item of this scale was "Over the next three months, people in my social network are likely to help me participate in regular physical activity."

\section{Emotional Coping Response}

The emotional coping response measurement was adapted from the emotional well-being subscale [49] and assessed how participants felt about their diabetes over the past month. Response options for the five-item scale ranged from "not at all" (1) to "very much" (5). An example from this scale was: "I am proud of how I'm coping with my diabetes."

\section{Behavioural Capacity}

Behavioural capacity was measured using four items on a 5-point Likert-type scale in which participants were asked 
to rate how confident they were in performing specific tasks within the last three months. Response options ranged from "never" (1) to "always" (5). A sample item for this scale developed for patients with chronic disease [50] was: "I can walk briskly for 20 minutes without stopping."

\section{Environment}

The environment measure was assessed using an adapted form of the International Physical Activity Prevalence Study Environmental Survey Module [51]. Seven items asked participants to rate on a 5-point Likert-type scale, with options ranging from "strongly disagree" (1) to "strongly agree" (5), how given statements described the area in which they lived. For example, "There are sidewalks on most of the streets in my local area."

\section{Observational Learning}

Observational learning was measured using two items previously used by Plotnikoff et al. [6] on a 5-point Likerttype scale in which participants were asked to rate how often they observed others being active in the last three months. Response options ranged from "never" (1) to "very often" (5), with an example item being, "I have observed people who are important to me engaging in regular physical activity."

\section{Satisfaction}

Participants randomized to the intervention group completed a 15-item satisfaction survey adapted from the Health $e$-steps Program [52]. The survey was completed immediately post intervention and asked participants to rate on a Likert-type scale the satisfaction/usability of the intervention website. Items included the credibility and content of the information on the website as well as satisfaction of various components of the website with response options ranging from "strongly disagree" (1) to "strongly agree" (5). Three open-ended questions were asked to assess the likes and dislikes and recommended changes to the website.

For all above measures, 'regular physical activity' was defined as doing at least 150 minutes of moderate intensity physical activity at the pace of brisk walking or faster (to include vigorous activity) each week.

\section{Data Analysis}

All analysis was conducted using SPSS (Version 12.0). Descriptive analysis (percentages and frequency counts) were conducted to assess retention, recruitment, adherence and satisfaction of the internet as a mode of delivery for physical activity information in the population.

Chi-square tests for independence were performed to examine group differences on pre-test categorical demographic scores. When applicable, demographic, health and computer usage variables were dichotomized into a 2 $\times 2$ table to ensure the minimum expected cell frequency was not violated.

Repeated measures analysis of covariance (RM ANCOVA) was conducted to compare the efficacy of the NetPLAY intervention to increase physical activity levels and all 11 physical activity-related cognitions. The dependent variables for the primary outcome consisted of scores calculated on the modified Godin Leisure-Time Exercise Questionnaire (GLTEQ) to assess: (1) MET.minutes; and (2) unweighted, combined moderate and vigorous minutes of physical activity. Participant baseline physical activity scores were used as a covariate in the above analyses. We employed intention to treat (last observation carried forward) for missing values at post-test. An examination of the diabetes literature suggests an association between BMI and physical activity behaviour in those with type 2 diabetes $[6,53]$. For example, Plotnikoff and colleagues [6] surveyed a sample of 1600 individuals with type 2 diabetes and found higher activity levels were associated with lower BMI $(\mathrm{p}<0.001)$, while Morrato and colleagues [53] found that for those with diabetes the probability of being active incrementally declined with each increasing BMI category. For this reason, along with the significant differences between the two study groups at baseline, BMI was included as a covariate (with baseline physical activity) in subsequent analysis for the primary behaviour outcome (i.e., physical activity).

\section{Results}

\section{Baseline characteristics}

Table 1 and Table 2 present the baseline data collected from a total of 49 participants (24 control, 25 intervention). The study groups did not statistically differ on any of the baseline characteristics measured with the exception of BMI $(\mathrm{p}<0.05)$ and outcome expectations $(\mathrm{p}<$ 0.05).

\section{Study Objective One: Study feasibility}

The first objective of Diabetes NetPLAY was to determine the feasibility of the internet as a mode of delivery for diabetes related physical activity information for individuals with type 2 diabetes, specifically examining recruitment, retention, adherence and satisfaction. Regarding recruitment, approximately 185 individuals were mailed study information packages and another 50 packages were directly given to individuals attending diabetes education classes at a local hospital. Of the 235 packages distributed, 78 individuals requested further information about the study, representing a response rate of $33 \%$. A total of 49 individuals consented to participate in the study, resulting in an overall recruitment rate of $21 \%$ (see Figure 1).

In terms of retention, two out of 25 participants from the intervention group did not complete the post-test 
Table I: Baseline socio-demographic and behavioural characteristics of study participants

\begin{tabular}{|c|c|c|c|c|}
\hline Variable & $\begin{array}{c}\text { Control }(N=24) \\
\text { Baseline } \\
\text { M(SD) }\end{array}$ & $\begin{array}{c}\text { Intervention }(\mathbf{N}=\mathbf{2 5}) \\
\text { Baseline } \\
\text { M (SD) }\end{array}$ & $\mathbf{t}$ & $\mathbf{p}$ \\
\hline Current Age & $54.5(10.8)$ & $53.7(9.8)$ & -0.3 & 0.805 \\
\hline Age when diagnosed & $47.5(11.0)$ & $46.5(10.0)$ & -0.3 & 0.746 \\
\hline Time (in months) living with diabetes & $86.6(90.8)$ & $86.9(100.8)$ & 0.0 & 0.992 \\
\hline BMI & $31.1(5.6)$ & $36.6(9.1)$ & 2.5 & 0.016 \\
\hline MET Minutes (per/wk) & $501(582.0)$ & $483(620.0)$ & -0.1 & 0.987 \\
\hline Unweighted Minutes (per/wk) & $111(123.0)$ & $105(140.0)$ & -0.2 & 0.769 \\
\hline RT minutes (per/wk) & $8(23.0)$ & $32(62.0)$ & 1.3 & 0.080 \\
\hline \multirow[t]{2}{*}{ Disability } & $2.2(1.5)$ & $2.8(1.9)$ & 1.1 & 0.261 \\
\hline & n (\%) & n (\%) & $\chi^{2}$ & \\
\hline \multicolumn{5}{|l|}{ Marital Status } \\
\hline Partner & $20(83.3 \%)$ & $13(52.0 \%)$ & 4.14 & 0.04 \\
\hline No Partner & $4(16.7 \%)$ & $12(48.0 \%)$ & & \\
\hline \multicolumn{5}{|l|}{ Residence } \\
\hline City & $20(83.3 \%)$ & $16(64.0 \%)$ & 1.46 & 0.23 \\
\hline Not city & $4(16.7 \%)$ & $9(36.0 \%)$ & & \\
\hline \multicolumn{5}{|l|}{ Education } \\
\hline No degree completed & $5(21.7 \%)$ & $9(36.0 \%)$ & 0.59 & 0.44 \\
\hline Degree completed & $18(78.3 \%)$ & $16(36.0 \%)$ & & \\
\hline \multicolumn{5}{|l|}{ Gross Family Income } \\
\hline$<\$ 20,000-\$ 59,000$ & 7 (30.4\%) & 12 (48.0\%) & 0.90 & 0.34 \\
\hline$\$ 60,000-<\$ 100,000$ & $16(69.6 \%)$ & $13(52.0 \%)$ & & \\
\hline \multicolumn{5}{|l|}{ Employment status } \\
\hline Not employed & 7 (29.2\%) & $9(37.5 \%)$ & 0.09 & 0.76 \\
\hline Employed & 17 (70.8\%) & $15(62.5 \%)$ & & \\
\hline \multicolumn{5}{|l|}{ Computer usage } \\
\hline Less than once/week & $10(66.7 \%)$ & $5(33.3 \%)$ & 0.60 & 0.44 \\
\hline More than once/week & $9(47.4 \%)$ & $10(52.6 \%)$ & & \\
\hline \multicolumn{5}{|l|}{ Computer usage } \\
\hline Less than $20 \mathrm{hrs} /$ month & $18(64.3 \%)$ & $10(35.7 \%)$ & 4.78 & 0.03 \\
\hline More than $20 \mathrm{hrs} / \mathrm{month}$ & $6(28.6 \%)$ & 15 (7I.4\%) & & \\
\hline
\end{tabular}

questionnaire, representing an attrition rate of $8 \%$. A total of three participants from the control group did not respond to the post-test questionnaire, signifying an attrition rate of $12.5 \%$ for this group (see Figure 1).

Adherence data showed that of the 25 participants randomized to the intervention group, 15 (60\%) accessed the website at least once per week for a minimum of eight weeks (i.e., per protocol criteria). Every participant in the intervention group logged onto the website at least once throughout the study. Intervention group hits to the website ranged from one to 121 with a median of 22 hits per person during the course of the study. Login frequency decreased in $60 \%(n=15)$ of the sample by study midpoint, $8 \%(n=2)$ stayed the same while $32 \%$ of participants actually increased their frequency of website access. Of those participants who decreased their visits to the website in the latter six weeks of the study, only four 
Table 2: Baseline social cognitive variables - between groups

\begin{tabular}{|c|c|c|c|c|c|}
\hline Social Cognitive Variable & $\begin{array}{c}\alpha(\text { or } r *) \\
\text { (\# of items) }\end{array}$ & $\begin{array}{c}\text { Control } n=24 \\
\text { Baseline } \\
\text { M(SD) }\end{array}$ & $\begin{array}{c}\text { Intervention } n=25 \\
\text { Baseline } \\
M(S D)\end{array}$ & $\mathbf{t}$ & $\mathbf{p}$ \\
\hline self-efficacy & $0.94(12)$ & $3.0(0.7)$ & $3.0(0.7)$ & -0.1 & 0.947 \\
\hline outcome expectations & $0.97(17)$ & $4.6(0.3)$ & $4.5(0.9)$ & -0.8 & 0.041 \\
\hline outcome expectancies & $0.88(17)$ & $2.7(0.3)$ & $2.7(0.3)$ & 0.2 & 0.810 \\
\hline self regulation & $0.74(3)$ & $3.9(0.5)$ & $3.8(0.5)$ & -0.9 & 0.392 \\
\hline situation & $0.88(17)$ & $2.1(0.5)$ & $2.4(0.7)$ & 1.7 & 0.120 \\
\hline reinforcement & $0.78(4)$ & $2.5(0.8)$ & $2.7(0.7)$ & 0.7 & 0.501 \\
\hline social support & $0.83(2)^{*}$ & $4.5(1.9)$ & $5.1(1.5)$ & 1.0 & 0.350 \\
\hline emotional coping resp. & $0.71(6)$ & $2.7(0.6)$ & $2.9(0.8)$ & 0.8 & 0.450 \\
\hline behavioural capacity & $0.85(4)$ & $3.2(0.9)$ & $3.1(1.2)$ & -0.5 & 0.632 \\
\hline environment & $0.77(7)$ & $3.6(0.9)$ & $3.5(0.9)$ & -0.4 & 0.699 \\
\hline observational learning & $0.29(2)^{*}$ & $3.8(1.3)$ & $4.1(0.8)$ & 1.0 & 0.331 \\
\hline
\end{tabular}

individuals dropped off their usage by more than half. Email counselling participation varied among participants in the intervention group, with one respondent initiating contact over 10 times while another recorded no contact with the counsellor. One hundred and ten messages were received by the study counsellor over the 12 week intervention, representing an average of 4.4 messages per participant. Subsequent analysis did not reveal any correlation between website adherence and physical activity among intervention participants.

The median satisfaction score was 4.19 with a range of 3.41 to 4.50 out of five. Eighty-six percent of individuals either "strongly agreed" or "agreed" that the website was user-friendly while $95.5 \%$ found the information on the website to be easy to understand and credible. The various components of the website had more variability in satisfaction with $68.2 \%$ of participants reporting they either "agreed" or "strongly agreed" that the weekly activities were useful, and $77.3 \%$ stated the same for their satisfaction of the email counselling component. A detailed account of the satisfaction scores are presented in Table 3.

\section{Study Objective Two: Preliminary efficacy} Intervention

Repeated measures of analyses of covariance (RM ANCOVA) for physical activity behaviour(including baseline physical activity as a covariate), revealed a significant group $\times$ time interaction for unweighted moderate and vigorous minutes of physical activity $[F(1,45)=4.00$, partial-eta squared $=0.08, \mathrm{p}=0.052]$ (see Table 4$)$, which according to Cohen represents a moderate effect size.[54] However, RM ANCOVA for physical activity behaviour did not reveal a significant group $\times$ time interaction for MET. minutes $[F(1,45)=1.88$, partial-eta squared $=0.04$, $\mathrm{p}<0.177]$. The intervention group participated in more unweighted moderate and vigorous minutes than the control group with a mean difference of 47 minutes (95\% CI $=-.37-102.66, \mathrm{p}<0.052$ ) (see Table 5). In addition the intervention group participated in more MET.minutes than the control group with a mean difference of 164 MET.minutes $(95 \% \mathrm{CI}=-83.12-436.87, \mathrm{p}<0.177)$. Although not included in our hypotheses, resistance training (including baseline RT as a covariate) was also examined. RM ANCOVA for these two variables did not reveal a significant group $\times$ time interaction (see Table 4 ).

Repeated measures of analyses of covariance (RM ANCOVA) for physical activity behaviour (using both baseline physical activity and BMI as covariates), revealed a significant group $\times$ time interaction for unweighted moderate and vigorous minutes $[F(1,44)=7.33$, partialeta squared $=.15, \mathrm{p}=0.010]$ and MET.minutes $[F(1,44)=$ 4.36 , partial-eta squared $=.09, \mathrm{p}<0.043]$ of total physical activity, which in both cases indicates a moderate-to-large effect size (see Table 4) [54]. The intervention group participated in more unweighted moderate and vigorous minutes of physical activity than the control group with a mean difference of 50 minutes $(95 \% \mathrm{CI}=18.27-125.22$, $\mathrm{p}<0.010$ ), further, the intervention group participated in more MET.minutes then the control group with a mean difference of 168 MET.minutes $(95 \% \mathrm{CI}=9.66-553.18$, $\mathrm{p}<0.043$ ) (see Table 5). Resistance training (using both baseline resistance training and BMI as covariates) did not reveal a significant group $\times$ time interaction effect (see Table 4).

Differences in social cognitive variables (see Table 6), controlling for baseline difference, showed a significant interaction effect for behavioural capacity $[F(1,44)=6.12$, partial-eta squared $=0.12, p<0.05]$. No other interactions were significant for the remaining social cognitive variables examined (i.e., self-efficacy, outcome expectations, outcome expectancies, self-regulation, situation, reinforcement, social support, emotional coping response, and observational learning).

The results for objective two were also analysed deleting the 5 cases ( 2 treatment; 3 controls) who did not complete the post-test. There were no meaningful differences in the 
Table 3: Satisfaction with intervention program

\begin{tabular}{lc}
\hline Variables & $\begin{array}{c}\text { Intervention Group } \mathbf{N}=\mathbf{2 2} \\
\text { Mean (SD) }\end{array}$ \\
\hline Website was user friendly & $4.27(0.70)$ \\
Overall presentation & $4.14(0.71)$ \\
Able to find way around & $4.23(0.75)$ \\
Information was easy to understand & $4.45(0.60)$ \\
Information was credible & $4.50(0.60)$ \\
Activities were useful & $3.86(0.94)$ \\
Message board was useful & $3.64(1.03)$ \\
Logbook was useful & $4.23(0.87)$ \\
Navigation links were easy & $4.05(0.72)$ \\
I liked the personal login & $4.27(0.63)$ \\
I liked being able to communicate with others & $3.41(1.05)$ \\
I liked the email counselling & $4.14(0.89)$ \\
\hline
\end{tabular}

Table 4: Physical activity behaviour $(n=47)$

\begin{tabular}{|c|c|c|c|c|c|c|c|}
\hline \multirow[b]{2}{*}{ Variable } & \multicolumn{2}{|c|}{ Control Group n = 24} & \multicolumn{2}{|c|}{ Intervention Group n $=23 *$} & \multirow[b]{2}{*}{$\mathbf{P}$ (for interaction) } & \multirow[b]{2}{*}{$\mathbf{F}$} & \multirow[b]{2}{*}{ eta $^{2}$} \\
\hline & $\begin{array}{l}\text { Time I } \\
\text { M (SD) }\end{array}$ & $\begin{array}{l}\text { Time } 2 \\
\text { M (SD) }\end{array}$ & $\begin{array}{l}\text { Time I } \\
\text { M (SD) }\end{array}$ & $\begin{array}{l}\text { Time } 2 \\
\text { M (SD) }\end{array}$ & & & \\
\hline MET minutes (per/wk) & $501(582)$ & $490(562)$ & $483(620)$ & $654(659)$ & 0.177 & 1.88 & 0.04 \\
\hline adjusted for BMI & & & & & 0.043 & 4.37 & 0.09 \\
\hline Unweighted mod \& vig (per/wk) & $111(123)$ & $92(93)$ & $105(140)$ & $140(138)$ & 0.052 & 4.00 & 0.08 \\
\hline adjusted for BMI & & & & & 0.010 & 7.33 & 0.15 \\
\hline RT minutes (per/wk) & $8(23)$ & $15(25)$ & $32(62)$ & $26(56)$ & 0.064 & 3.60 & 0.07 \\
\hline adjusted for BMI & & & & & 0.061 & 3.70 & 0.08 \\
\hline
\end{tabular}

* Two individuals did not complete baseline Godin measures, therefore, not allowing the last observation to be carried forward technique to be employed. $M=$ mean; $S D$ = standard deviation; Vig = vigorous; Mod = moderate

results between the deletion and the last observation carried forward techniques. Further, we re-ran the main analyses, adjusting for computer usage (i.e., proficiency of computer use and number of hours/week on the computer), which did not alter the current results.

\section{Discussion}

The first objective of this study was to determine the feasibility (recruitment, retention, adherence and satisfaction) of the internet in the delivery of physical activity related information to individuals with type 2 diabetes. There is an increasing need to deliver cost-effective physical activity interventions to large numbers of individuals living with this chronic disease. With internet and email becoming a primary mode of communication, an opportunity exists to utilize information technology to elicit physical activity behaviour change.

Recruitment for the Diabetes NetPLAY study did prove to be challenging. Various recruitment methods were employed to attract potential participants including newspaper ads, posters, internet ads and in-person visits to Diabetes Education Centres. Recruitment continued over a four month period with more than 200 study informa- tion packages distributed. A large proportion of individuals reported hesitation with using the internet or not having regular access to a computer as reasons for not participating. Although internet usage is continuing to rise, there are still a number of individuals with limited or no internet experience. Lack of interest in physical activity, the 12 week time commitment and the chance of being randomized to the control group were also cited as reasons for not participating in the study. Similar studies have also encountered difficulty in recruiting participants. Napolitano and colleagues [13] had 275 individuals express interest in their internet-based physical activity intervention, but after repeated attempts, only 96 of those participants responded to follow-up. Tate also encountered low recruitment rates in their internet weight loss program in which 196 individuals responded to the study but only 114 followed up with screening. [15]

Results demonstrated that retention of participants to the Diabetes NetPLAY website was high. Forty-four participants completed the post-test questionnaire, representing a $90 \%$ retention rate for this study. Similar studies have also demonstrated comparable retention rates. The D-Net intervention by McKay and colleagues [11] revealed a 
Table 5: Change Scores $(n=47)$

\begin{tabular}{|c|c|c|c|c|c|c|}
\hline \multirow[t]{2}{*}{ Variable } & \multirow[t]{2}{*}{ Change score (between group) } & \multicolumn{2}{|c|}{ 95\% Confidence Interval } & \multirow[t]{2}{*}{$\mathbf{t}$} & \multirow[t]{2}{*}{$\mathbf{p}$} & \multirow[t]{2}{*}{ eta $^{2}$} \\
\hline & & Lower Bound & Upper Bound & & & \\
\hline MET.minutes (per/wk) & 164 (97) & -83.12 & 436.87 & 1.37 & 0.177 & 0.04 \\
\hline adjusted for BMI & $168(85)$ & 9.66 & 553.18 & 2.09 & 0.043 & 0.09 \\
\hline unweighted mod. \& vig mins (per/wk) & $47(45)$ & -0.370 & 102.00 & 2.00 & 0.052 & 0.10 \\
\hline adjusted for BMI & $50(44)$ & 18.27 & 125.22 & 2.71 & 0.010 & 0.15 \\
\hline
\end{tabular}

Table 6: Social cognitive variables $(n=49)$

\begin{tabular}{|c|c|c|c|c|c|c|c|}
\hline \multirow[b]{2}{*}{ Variable } & \multicolumn{2}{|c|}{$\begin{array}{c}\text { Control Group } \\
n=24\end{array}$} & \multicolumn{2}{|c|}{$\begin{array}{c}\text { Intervention Group } \\
n=25\end{array}$} & \multirow[b]{2}{*}{$\mathbf{p}$} & \multirow[b]{2}{*}{$\mathbf{F}$} & \multirow[b]{2}{*}{ eta ${ }^{2}$} \\
\hline & $\begin{array}{l}\text { Time I } \\
\text { M (SD) }\end{array}$ & $\begin{array}{l}\text { Time } 2 \\
\text { M (SD) }\end{array}$ & $\begin{array}{l}\text { Time I } \\
\text { M (SD) }\end{array}$ & $\begin{array}{l}\text { Time } 2 \\
\text { M (SD) }\end{array}$ & & & \\
\hline Self-efficacy & $3.01(0.71)$ & $2.82(0.84)$ & $3.00(0.74)$ & $2.99(0.84)$ & 0.311 & 1.05 & 0.02 \\
\hline Outcome expectations & $4.62(0.37)$ & $4.57(0.42)$ & $4.46(0.87)$ & $4.57(0.54)$ & 0.763 & 0.92 & 0.00 \\
\hline Outcome expectancies & $2.71(0.34)$ & $2.65(0.36)$ & $2.73(0.29)$ & $2.69(0.39)$ & 0.799 & 0.07 & 0.00 \\
\hline Self-regulation & $3.94(0.53)$ & $3.75(1.05)$ & $3.81(0.54)$ & $3.56(0.91)$ & 0.550 & 0.36 & 0.00 \\
\hline Situation & $2.11(0.55)$ & $2.16(0.59)$ & $2.41(0.66)$ & $2.35(0.67)$ & 0.406 & 0.71 & 0.02 \\
\hline Reinforcement & $2.58(0.84)$ & $2.70(0.91)$ & $2.73(0.66)$ & $2.83(0.74)$ & 0.961 & 0.00 & 0.00 \\
\hline Social support & $4.58(1.99)$ & $4.27(2.05)$ & $5.06(1.52)$ & $4.18(2.10)$ & 0.201 & 1.69 & 0.04 \\
\hline Emotional coping resp. & $2.78(0.67)$ & $2.90(0.67)$ & $2.93(0.76)$ & $2.90(0.67)$ & 0.733 & 0.12 & 0.00 \\
\hline Behavioural capacity & $3.25(0.98)$ & $2.97(0.98)$ & $3.10(1.18)$ & $3.23(1.32)$ & 0.001 & 7.63 & 0.14 \\
\hline Observational learning & $3.83(1.32)$ & $3.31(1.31)$ & $4.14(0.78)$ & $3.96(0.92)$ & 0.087 & 3.05 & 0.06 \\
\hline
\end{tabular}

retention rate of $87 \%$ at the 8 -week follow-up point. Similarly, Napolitano et al. [13] showed retention rates of $88 \%$ and $80 \%$ at one- and three-month follow-ups, respectively. Finally, $86 \%$ of participants completed the six-week pilot intervention conducted by Richardson and colleagues [22]. However, in a recent review by Vandelanotte, Spathonis, Eakin and Owen [8], they reported retention rates to be lower, with an overall average of $73 \%$ attrition.

In the review by Vandelanotte and colleagues [8], adherence to internet-based physical activity interventions has been low. Of the five studies that reported objective data, all indicated a decline in website usage as the intervention progressed. In the Diabetes NetPLAY study, over half the intervention group $(60 \%)$ showed a decline in login frequency while, interestingly, $32 \%$ of participants actually increased their usage of the intervention website after the study mid-point. As with non-internet-based studies, adherence continues to be a challenge in the long-term.

The D-Net diabetes self-management program [18], showed a significant decrease in login frequency $(50 \%)$ during the 10 month intervention. The highest rates of website usage were recorded within the first three months of the program with a gradual drop-off over time. Leslie and colleagues [55] reported on the engagement and retention of participants in the Active Living Online study
[56]. Over the 8-week intervention, only $46 \%$ of recruited participants visited the website with $77 \%$ of those hits recorded in the first 2 weeks of the intervention. The relatively low level of website interactivity may have contributed to the low adherence rates demonstrated in the Active Living Online study, as many participants felt it unnecessary to continue visiting a static website.

In addressing the adherence issue, one might want to consider the interactive features of a physical activity website. Increasing the interactivity of these types of interventions has been suggested in the literature as important components to incorporate into the website design $[13,55]$. Email, chat rooms, on-line logbooks and updated information may be simple features that aid in the adherence of participants to a physical activity website.

Our Diabetes NetPLAY study used several interactive techniques in an attempt to keep study participants engaged. Individualized emails were sent on a weekly basis, providing general feedback on the specific topic of the week, progress and motivation. An on-line logbook allowed participants to track their progress and receive feedback from their counsellor on how they were doing. The study website was also updated on a weekly basis, with past weeks being archived for future reference. The study message board had various topics posted by the study counsellor at which point, participants could share their thoughts and 
feelings with others involved in the study. These features may have given participants reason to continue visiting the website on a regular basis throughout the study.

Previous studies have reported a positive correlation between login frequency and behaviour change. Tate, Wing and Winnett [15] found a significant correlation ( $\mathrm{p}$ $<0.01$ ) between login frequency and weight change between 0 and 6 months time in both the intervention and control groups. While McKay et al. [11] found a significant relation between website usage and greater change in moderate-to-vigorous physical activity within their 8-week intervention. Website usage in this study was monitored by the number of hits to the Diabetes NetPLAY website by each participant. Analysis failed to show a positive association between website usage and physical activity behaviour change. In other words, those who visited the website more frequently didn't report an increase in physical activity behaviour than those who used it less often. Perhaps, there is a threshold regarding the extent to which accessing information yields corresponding behaviour change gains.

Satisfaction among intervention participants for this mode of delivery was positive. Participants indicated they were more satisfied with the personal email counselling than the peer-to-peer support through the message board. A similar finding was also captured by McKay and colleagues [11] with $88 \%$ of participants reporting satisfaction with a personal coach versus $35 \%$ reported for peerto-peer support. Additional promotion and encouragement may be needed to generate strong peer-to-peer support systems with this mode of delivery.

Slightly less than half (49\%) of study participants reported using the internet on a daily basis while at the same time $43 \%$ reported using the internet less than 9 hours in the previous month. This may indicate that while individuals are accessing the internet on a regular basis, they are not spending comparative amounts of time surfing the web. This might be an important aspect to consider when developing further web-based studies as individuals may not be accustomed to spending the required time on study websites to take full advantage of their behaviour change potential.

The second study objective was to determine the preliminary efficacy of the internet as a mode of delivery for eliciting recommended changes in physical activity related cognitions and behaviours for individuals with type 2 diabetes. The results demonstrate that the internet and interactive technology is an efficacious vehicle for promoting physical activity behaviour change among individuals with type 2 diabetes. The intervention group significantly increased their mean total physical activity levels whereas the control group demonstrated a decline in activity lev- els. Although not all participants in the intervention reached recommended guidelines within the parameters of this study, participants did demonstrate a gradual progression towards the clinical recommendations. The Canadian Diabetes Association [4] recommends individuals with type 2 diabetes gradually increase their activity levels to 150 minutes of moderate intensity, physical activity per week.

The physical activity changes demonstrated in this study have both research and clinical significance. Although our sample size was small, moderate to large effect sizes were demonstrated for physical activity behaviour. Additionally, the weekly average increase of 47 minutes in physical activity behaviour over the course of the study among the intervention group participants has very important practical and clinical implications for public health. The need for cost-effective physical activity interventions that can reach large numbers of people is vital in the public health system. Therefore, these results can also be viewed as meaningful at a population level.

A systematic review of the literature suggests modest effects for the efficacy of web-based physical activity interventions, with just over half of the studies reporting significant positive behavioural changes [8]. Only a few studies have shown effects on physical activity behaviour $[13,19,57]$ while others with [58] or without tailored feedback $[15,56,59]$ have shown no effects on physical activity behaviour. The Diabetes NetPLAY study was able to demonstrate group and time effects with moderate to large effect sizes for physical activity behaviour change, despite having a small sample size.

Plotnikoff et al. [19] found similar results in a workplace context over the same time period. Although effect sizes were small, intervention participants showed an increase in total activity levels at 3 months while activity levels of control participants declined during the same time frame. Likewise, Napolitano and colleagues [13] found that after one month of exposure to an SCT-grounded physical activity website and weekly email tip sheets, intervention participants exhibited higher levels of moderate physical activity and walking minutes compared to the control group. However, at the three-month time-point, only walking minutes remained significant between the two groups.

Similar findings to the Diabetes NetPLAY study were also demonstrated in a study of 434 healthy adults [57]. Researchers found a significant group $\times$ time interaction effect in favour of both intervention groups (with or without repeated feedback) for active transportation and leisure-time physical activity compared with the control group. However, in contrast to Diabetes NetPLAY, Vandelanotte et al. [8] were able to show behaviour changes over a longer study period of 6 months. 
The Diabetes Network (D-Net) Active Lives Physical Activity Intervention [11] also demonstrated comparable findings to that of Diabetes NetPLAY. Significant time effects in both walking and moderate-to-vigorous intensity physical activity were found at the end of the 8-week study. Unlike NetPLAY, however, McKay and colleagues [11] failed to show a significant difference in physical activity behaviour between intervention and control groups over a shorter period of time. Interestingly, the D-Net study allowed the control group access to diabetes-specific articles in the website library in addition to real-time glucose tracking with graphic feedback for the duration of the 8week study. Control participants could have been motivated and guided by information accessed through the virtual library and therefore, increased their physical activity behaviour as well.

The significant changes in physical activity behaviour among intervention participants in the Diabetes NetPLAY study may be attributed to several factors. First, individuals may have already been motivated to participate in physical activity prior to study initiation. The simple fact that individuals were interested in participating in a physical activity study may speak to the stage of readiness that many of the participants were in prior to starting the intervention. Second, web-based interventions are still seen as a novel approach for the delivery of health-related physical activity and counselling information. Therefore, participants could have been motivated to increase their physical activity behaviour, in part, because of the novel mode of delivery and not the information, per se. This speaks to the importance of further research in this area.

The intervention group in our study also demonstrated an increase in behavioural capacity (i.e., self-reported ability to complete various physical tasks) over the course of the 12-week study. Participants in the intervention group felt they were better able to complete physical tasks like walking and jogging after taking part in Diabetes NetPLAY. However, there were no significant increases in any other physical activity related cognitions. These findings contrast similar studies grounded in theoretical concepts. Plotnikoff and colleagues [19] measured several physical activity-related cognitions from a variety of social cognitive theories. Following the 12-week study, participants in the intervention group were more efficacious in four out of the seven social-cognitive variables measured, including self-efficacy.

The fact the majority of physical activity-related cognitions did not significantly change in this study may be explained by the response shift theory concept. Borrowed from the quality of life domain, this concept proposes that an individual's self-perception and/or internal standards (e.g., self-regulation, outcome expectations) shift as the result of a change in a measurable behaviour (e.g., physi- cal activity) [60]. In other words, as an individuals behaviour changes (i.e., they become more active), they encounter new situations, barriers etc. as a result, causing a shift in their cognitions related to that particular behaviour (i.e., physical activity). Examination of the response shift theory has occurred primarily in the quality of life domain; therefore, additional research in the social cognitive field is needed to evaluate its true effectiveness in the physical activity domain.

A second explanation for the lack of change in behaviourrelated cognitions could be attributed to elevated selfreport measures at baseline. This could have produced a ceiling effect, leaving limited room for improvement in these social cognitive variables.

Strengths of this study include, first, the comprehensive use of a theoretically-based framework in the messaging and composition of the website tools. The use of theoretically-based interventions may strengthen program outcomes and facilitate successful behaviour change $[61,62]$. Second, the use of SCT in its entirety for the design of a web-based program is a unique feature as compared to a large portion of the programs which tend to operationalize only specific components of social cognitive theories. Finally, this study contributes to the growing body of literature of web-based mediums for the delivery of health information. The use of interactive features such as linked email counselling, message boards, and logbooks are important tools in the further development of knowledge in this area.

This study, however, is not without its limitations. Although we were able to detect physical activity behaviour differences, the limited sample size may have prevented the detection of differences between many social cognitive variables, as this pilot study was not sufficiently powered [54]. The lack of objective physical activity measures and the dependence on self-report indicators could be considered a limitation [63]. The use of objective physical activity and health status measures, such as accelerometers and blood tests respectively, would be important for future studies on this topic. Although we did see an increase in physical activity behaviour among the intervention participants, we were not able to tease out the effects of the SCT messaging versus other components of the website. Therefore, it is difficult to pinpoint which components/messages had the most, if any, effect. Finally, there was no long-term follow-up which prevented an evaluation of the intervention's long-term efficacy.

Future research should explore the use of web-based interventions to sustain long-term behaviour change within a broad range of demographic categories. Researchers should attempt to recruit and engage larger samples of individuals with type 2 diabetes over the longer-term. 
Additionally, future studies may benefit from the inclusion of various follow-up assessments including process evaluations (e.g., focus groups, interviews) and detailed statistics (e.g., frequency and duration of access) related to patterns of website use. Results of such feedback could further inform the utility and applicability of such websites. Further exploration in the grounding of messages and information in specific health behaviour change theories and models is an important step likely to improve the success of such interventions. The use of other social cognitive theories and models as frameworks for further web-based interventions should also be considered in future research. Further, multi-level, ecological (i.e., social, organizational, community, policy, and built environmental) strategies should also be considered for implementation with individual-based, web-based approaches to elicit physical activity behaviour change in this population.

Tailored messaging and interactive website features should be examined to further determine if such elements can maintain long-term engagement and adherence to programming. Increasing the usage of various internet items (i.e., message board, logbook) should be explored in further detail to examine their effects on successful behaviour change in this population.

Examining the use of algorithms in the design of webbased physical activity interventions would also be of value. Allowing participants to receive instantaneous, tailored feedback may increase adherence and physical activity behaviour change. In addition, the use of graphs or charts to provide visual feedback on behaviour change may appeal to and further motivate participants. Future studies should track website usage through a variety of methods including length of time participants spend viewing website pages and their specific use of the website applications.

Finally, the use of the internet to deliver behaviourchange interventions could present additional barriers for some individuals. Therefore, it would be beneficial for researchers to determine how to better relate with participants and understand the barriers-to-use so as to better appeal to more individuals.

In summary, this study revealed the web-based delivery of physical activity programs holds particular promise for behaviour change in the diabetes population. The expanding availability of the internet allows such programs to reach large numbers of individuals while at the same time providing instantaneous support and feedback. Although in its relative infancy, web-based physical activity interventions, such as NetPLAY, are important in the development and expansion of future research in this area.

\section{Competing interests}

The authors declare that they have no competing interests.

\section{Authors' contributions}

TL and RCP conceived the study. RCP, TL, KSC and NB were involved in the survey design. TL coordinated survey delivery and data collection. TL analyzed the data. TL, RCP, KSC and NB interpreted the data. TL and RCP were responsible for drafting the manuscript. All authors critically evaluated the article for content and approved the final version.

\section{Acknowledgements}

This study was funded by the Alberta Diabetes Institute.

\section{References}

I. Sigal RJ, Kenny GP, Wasserman DH, Castaneda-Sceppa C: Physical activity/exercise and type 2 diabetes. Diabetes Care 2004, 27:2518-2539.

2. Ivy JL, Zderic TW, Fogt DL: Prevention and treatment of noninsulin-dependent diabetes mellitus. Exercise \& Sport Sciences Reviews 1999, 27: I-35.

3. Hu FB, Stampfer MJ, Solomon C, Liu S, Colditz GA, Speizer FE, et al:: Physical activity and risk for cardiovascular events in diabetic women. Annals of Internal Medicine 200I, 134:96-105.

4. Canadian Diabetes Association Clinical Practice Guideline Expert Committee (CDA): Canadian Diabetes Association 2003 clinical practice guidelines for the prevention and management of diabetes in Canada. Can J Diabetes 2003, 27(Suppl 2): I- I52.

5. Kirk A, Mutrie N, Maclntyre P, Fisher M: Increasing physical activity in people with type 2 diabetes. Diabetes Care 2003, 26: II86-II92.

6. Plotnikoff RC, Taylor LM, Wilson PM, Courneya K, Sigal RJ, Birkett N, et al.: Factors associated with physical activity in adults with type I or type 2 diabetes. Medicine and Science in Sports \& Exercise 2006, 38:1526-1534.

7. McKay HG, Feil EG, Glasgow RE, Brown JE: Feasibility and use of an internet support service for diabetes self-management. The Diabetes Educator 1998, 24: 174- 179.

8. Vandelanotte C, Spathonis KM, Eakin EG, Owen N: Website-delivered physical activity interventions: $A$ review of the literature. American Journal of Preventive Medicine 2007, 33:54-62.

9. Kim C, Kang D: Utility of a web-based intervention for individuals with type 2 diabetes: The impact on physical activity levels and glycemic control. Computer Information Nursing 2006, 24(6):337-335.

10. Marcus BH: A tailored internet intervention did not increase physical activity more than a tailored print intervention or publicly available web sites. Evidence-Based Nursing 2008, I I:I3.

II. McKay HG, King D, Eakin EG, Seeley JR, Glasgow RE: The diabetes network internet-based physical activity intervention: A randomized pilot study. Diabetes Care 200I, 24:I328-1334.

12. Statistics Canada: Household internet use survey (2003). [http:/ /www.statcan.gc.ca/pub/56m0002g/56m0002g200400l-eng.pdf].

13. Napolinato MA, Fotheringham M, Tate D, Sciamanna C, Leslie E, Owen N, et al.: Evaluation of an internet-based physical activity intervention: A preliminary investigation. Annals of Behavioural Medicine 2003, 25:92-99.

14. Fotheringham MJ, Owies D, Leslie E, Owen N: Interactive health communication in preventive medicine: Internet-based strategies in teaching and research. American Journal of Preventive Medicine 2000, 19:113-120.

15. Tate DF, Wing RR, Winnett RA: Using internet technology to deliver a behavioural weight loss program. JAMA 200I, 285: $1172-1177$.

16. Tate DF, Jackvony EH, Wing RR: Effects of internet behavioural conselling on weight loss in adults at risk for type 2 diabetes: A randomized trial. JAMA 2003, 289:1833-1836.

17. Oenema A, Tan F, Brug J: Short-term efficacy of a web-based computer-tailored nutrition intervention: Main effects and mediators. Annals of Behavioural Medicine 2005, 29:54-63. 
18. Glasgow RE, Boles SM, McKay HG, Feil EG, Barrera M Jr: The D-Net diabetes self-management program: long-term implementation, outcomes, and generalization results. Preventive Medicine 2003, 36(4):410-419.

19. Plotnikoff RC, McCargar LJ, Wilson PM, Loucaides CA: Efficacy of an email intervention for the promotion of physical activity and nutrition behaviour in the workplace context. American Journal of Health Promotion 2005, 19:422-429.

20. Rovniak LS, Hovell MF, Wojcik JR, Winett RA, Martinez-Donate AP: Enhancing theoretical fidelity: An email-based walking program demonstration. American Journal of Health Promotion 2005, 20:85-95.

21. Kaufman N, Kaufman A: Internet-based physical activity coaching. Diabetes 2007, 56:A229-230.

22. Richardson CR, Mehari KS, Mclntyre LG, Janney AW, Fortlage LA, Sen $A$, et al.: A randomized trial comparing structured and lifestyle goals in an internet-mediated walking program for people with type 2 diabetes. International Journal of Behavioral Nutrition and Physical Activity 2007, 4:59.

23. Yoo J, Lee H, Kim C: Development and validation of a computerized exercise intervention program for patients with type 2 diabetes mellitus in Korea. Yonsei Med J 2003, 44(5):892-904.

24. Eng TR, Gustafson DH, Henderson J, Jimison H, Patrick K: Introduction to evaluation of interactive health communication applications. American Journal of Preventive Medicine 1999, 16:10-15.

25. Baranowski T, Anderson C, Carmack C: Mediating variable framework in physical activity intervention. How are we doing? How might we do better? American Journal of Preventive Medicine 1998, 15:266-297.

26. Bandura A: Social foundations of thought and action New Jersey: Prentice-Hall; 1986

27. Bandura A: Self-efficacy, the exercise of control New York: W.H. Freeman; 1997.

28. Bandura A: Health promotion by social cognitive means. Health Education and Behaviour 2004, 31:143-164.

29. Baranowski T, Perry CL, Parcel GS: How individuals, environments, and health behaviour interact: Social cognitive theory. In Health Behvaviour and Health Education 3rd edition. Edited by: Glanz K, Rimer BK, Lewis FM. San Francisco, CA: Jossey-Bass; 2002:165-184.

30. Marcus BH, King TK, Clark MM, Pinto BM, Bock BC: Theories and techniques for promoting physical activity behaviours. Sports Medicine 1996, 22(5):32I-33I.

31. Keller C, Fleury J, Gregor-Holt N, Thompson T: Predictive ability of social cognitive theory in exercise research: An integrated literature review. The Online Journal of Knowledge Synthesis for Nursing 1999, E6(2): 19-31.

32. Allen NA: Social cognitive theory in diabetes exercise research: An integrative review. The Diabetes Educator 2004, 30:805-819.

33. Tudor-Locke C, Bell RC, Myers AM, Harris S, Ecclestone NA, Lauzon $\mathrm{N}$, et al.: Controlled outcome evaluation of the First Step Program: A daily physical activity intervention for individuals with type II diabetes. International Journal of Obesity 2004, 28:II3-II9.

34. DiLoreto C, Fanelli C, Lucidi P, Murdolo G, De Cicco A, Parlanti N, et al:: Validation of a counseling strategy to promote the adoption and the maintenance of physical activity by type 2 diabetic subjects. Diabetes Care 2003, 26:404-408.

35. Canadian Society for Exercise Physiology: Physical Activity Readiness Questionnaire (PAR-Q). [http://www.confmanager.com/ communities/c574/files/hidden/pdfs/par-q.pdf].

36. Statistics Canada: Canada's ethnocultural portrait: The changing mosaic. [http://www.statcan.gc.ca/bsolc/olc-cel/olccel?catno $=97 F 0010 X \&$ lang=eng].

37. Health Canada: Canadian Guidelines for Body Weight Classification in Adults. [http://www.hc-sc.gc.ca/fn-an/alt formats/hpfbdgpsa/pdf/nutrition/weight book-livres des poids-eng.pdf].

38. Godin G, Shephard RJ: Godin Leisure-Time Exercise Questionnaire. Medicine and Science in Sport and Exercise 1985, 17:s36-s38.

39. Jacobs DR Jr, Ainsworth BE, Hartman TJ, Leon AS: A simultaneous evaluation of 10 commonly used physical activity questionnaires. Medicine and Science in Sports and Exercise 1993, 25:8I-91.

40. Brown WJ, Bauman AE: Comparison of estimates of population levels of physical activity using two measures. Australian and New Zealand Journal of Public Health 2000, 24:520-525.
41. Plotnikoff R, Lippke S, Courneya K, Birkett N, Sigal R: Physical activity and social-cognitive theory: $A$ test in a population sample of adults with type I or type 2 diabetes. Applied Psychology: An International Review 2008, 57(4):628-643.

42. Marcus BH, Rakowski W, Rossi JS: Assessing motivational readiness and decision making for exercise. Health Psychology 1992, I I:257-26I.

43. Plotnikoff RC, Hotz S, Birkett N, Courneya K: Exercise and the transtheoretical model: A longitudinal test of a population sample. Preventive Medicine 200I, 33:44I-452.

44. Lewis CE, Raczynski J, Heath GW, Levinson R, Hilyer JC Jr, Cutter GR: Promoting physical activity in low-income AfricanAmerican communities: The PARR project. Ethn Dis 1993, 3:106-118.

45. Mullan E, Markland D, Ingledew DK: A graded conceptualization of self-determination in the regulation of exercise behaviour: Development of a measure using confirmatory factor analytic procedures. Personality and Individual Differences 1997, 23:745-752.

46. Rogers LQ, Shah P, Dunnington G, Greive A, Shanmugham A, Dawson B, Courneya KS: Social cognitive theory and physical activity during breast cancer treatment. Oncology Nuring Forum 2005, 32:807-815.

47. Marcus BH, Rossi JS, Shelby VC, Niaura RS, Abrams DB: The stages and processes of exercise adoption and maintenance in a worksite sample. Health Psychology 1992, I I:386-395.

48. Courneya KS, Plotnikoff RC, Hotz S, Birkett N: Social support and the theory of planned behaviour in the exercise domain. American Journal of Health Behavior 2000, 24:300-308.

49. Yellen SB, Cella DF, Webster K, Blendowski C, Kaplan E: Measuring fatigue and other anemia-related symptoms with the Functional Assessment of Cancer Therapy (FACT) measurement system. Journal of Pain and Symptom Management 1997, 13:63-74.

50. Rogers LQ, Humphries M, Davis H, Gutin B: Predictors of physical activity among internal medicine clinic patients [abstract]. Medicine and Science in Sports and Exercise 1998, 30(Suppl 5):96.

5I. IPAQ: International Physical Activity Prevalence Study Environmental Survey Module. [http://www-rohan.sdsu.edu/faculty/ sallis/IPAQIPS.pdf].

52. Steele R: Using the internet in physical activity promotion: $A$ randomized control trial of intervention delivery modes. In PhD Thesis Central Queensland University, Faculty of Engineering, Science and Health, School of Health and Human Performance; 2006.

53. Morrato EH, Hill JO, Wyatt HR, Ghushchyan V, Sulivan PW: Physical activity in U.S. adults with diabetes and at risk for developing diabetes. Diabetes Care 2007, 30:203-209.

54. Cohen J: Statistical power analysis for the behavioural sciences Hillsdale, NJ: Erlbaum; 1988.

55. Leslie E, Marshall AL, Owen N, Bauman A: Engagement and retention of participants in a physical activity website. Preventive Medicine 2005, 40:54-59.

56. Marshall AL, Leslie ER, Bauman AE, Marcus BH, Owen N: Print versus website physical activity programs: $A$ randomized trial. American Journal of Preventive Medicine 2003, 25:88-94

57. Spittaels H, De Bourdeaudhuij I, Vandelanotte C: Evaluation of a website-delivered computer-tailored intervention for increasing physical activity in the general population. Preventive Medicine 2007, 44(3):209-17.

58. McKay HG, Glasgow RE, Feil EG, Boles SM, Barrera M Jr: InternetBased Diabetes Self-Management and Support: Initial Outcomes from the Diabetes Network Project. Rehabilitation Psychology 2002, 47(I):3I-48.

59. Harvey-Berino J, Pintauro $S$, Buzzel $P$, et al.: Does using the internet facilitate the maintenance of weight loss? International Journal of Obesity 2002, 26:1254-1260.

60. Sprangers MAG, Schwartz CE: Integrating response shit into health-related quality of life research: A theoretical model. Social Science and Medicine 1999, 48:1507-15I5.

6I. Green J: The role of theory in evidence-based health promotion practice. Health Education Research 2000, I5(2): I25-129.

62. Doshi A, Patrick K, Sallis JF, Calfas K: Evaluation of physical activity web sites for the use of behaviour change theories. Annals of Behavioural Medicine 2003, 25: I05-III.

63. Warnecke RB, Johnson TP, Chavez N, Sudman S, O'Rourke DP, Lacey $\mathrm{L}$, Horm J: Improving question wording in surveys of culturally diverse populations. Annals of Epidemiology 1997, 7:334-342. 